otherwise indicated. ${ }^{34}$ From the results of this study a definite statement on the committee's "two hour rule" is not possible based on the relatively low total numbers of injections. However, the single anaphylactic reaction occurred well within this generally accepted 30 minute observation period. Previous studies suggest that virtually all serious delayed reactions occurred in asthmatic patients, ${ }^{51718}$ so if these patients are specifically excluded a two hour wait for all patients after each injection seems unnecessary.

Thus patient selection for immunotherapy is of the utmost importance. Injections should be given only where there is access to emergency drugs (especially adrenaline) and other resuscitative facilities. People giving the injections should be trained or be under the supervision of doctors trained in immunotherapy. Under these conditions any reactions would be self evident within a very short time after the injection if they were likely to be life threatening.

We conclude that injection immunotherapy with a biologically standardised extract in patients with severe pollen allergy should be considered in those who fail to respond adequately to conventional drug treatment. Patients should be carefully selected and the procedure carried out in a specialised centre.

We thank Allergologisk Laboratorium (ALK Denmark) for supplying Alutard SQ and placebo treatment packs, the Wellcome Foundation for supplying acrivastine $8 \mathrm{mg}$ capsules (Semprex), and Miss Jane Norris-Hill (Pollen Research Project, Polytechnic of North London) for the pollen counts. We particularly thank our patients for their unfailing commitment to the study and their good humour.
1 Fleming DM, Crombie DL. Prevalence of asthma and hay fever in England and Wales. BMF 1987;294:279-83.

2 Howarth PH. Allergic rhinitis: a rational choice of treatment. Respir Med 1989;83:179-88.

3 World Health Organisation/International Union of Immunological Societie Working Group. Current status of allergen immunotherapy. Shortened version of a World Health Organisation/International Union of Immunological Societies Working Group report. Lancet 1989;i:259-61.

4 Malling H-J. Immunotherapy position paper. Allergy 1988;43 (suppl 6):9-31.

5 Anonymous. CSM update. Desensitising vaccines. BMJ 1986;293:948.

6 Frankland AW, Augustin R. Prophylaxis of summer hay-fever and asthma. A controlled trial comparing crude grass-pollen extracts with the isolated main controlled trial comparing crude grass-poll

$7 \mathrm{Kerr} \mathrm{JW}$, Murchison LE. A controlled trial of pollen adsorbate in the treatment of hay fever. Scott Med F 1963;8:485.
.

8 Miller ACML, Tees EC. A metabolizable adjuvant: clinical trial of grass pollen-tyrosine adsorbate. Clin Allergy 1974;4:49-55.

9 Osterballe O. Nasal and skin sensitivity during immunotherapy with two major allergens 19,25 and partially purified extract of timothy grass pollen Allergy 1982;37:169-77.

10 Osterballe $\mathrm{O}$. Immunotherapy in hay fever with two major allergens 19,25 an partially purified extract of timothy grass pollen. A controlled double-blin study. In vivo variables. Season 1. Allergy 1980;35:473-89.

11 Mosbech H, Osterballe O. Does the effect of immunotherapy last after termination of treatment? Follow-up study in patients with grass pollen rhinitis. Allergy 1988;43:523-9.

12 Juniper EF, Frith PA, Dunnett C, Cockcroft DW, Hargreave FE. Reproducibility and correlation of responses to inhaled histamine and methacholine. Thorax 1978;33:705-10.

13 Gjesing B, Jaeger L, Marsh DG, Lowenstein H. The international collaborative study establishing the first international standard for timothy (Phleum study establishing the first international standard for timothy (Phleum 67.

14 Moller C, Bjorksten B, Nilsson G, Dreborg S. The precision of the conjunctival provocation test. Allergy 1984;39:37.

15 Armitage P, Berry G. Distribution free methods. In: Statistical methods in medical research, 2nd ed. Oxford: Blackwell Scientific Publications, 1987: 408-20.

16 Armitage P, Berry G. Statistical inference. In: Statistical methods in medical research. 2nd ed. Oxford: Blackwell Scientific Publications, 1987:93-140.

17 Rawlins MD, Wood SM, Mann RD. Hazards with desensitising vaccines. In: Kurth R, ed. Regulatory control and standardization of allergenic extracts Stuttgart: Springer Verlag, 1988:147-51. (5th international Paul Ehrlich seminar, September 1987.)

18 Lockey RF, Benedict LM, Turkeltaub PC, Bukantz SC. Fatalities from immunotherapy (IT) and skin testing (ST). $f$ Allergy Clin Immunol immunotherapy

(Accepted 21 November 1990)
Margaret Pyke Centre for the Study and Training of Family Planning, London WIV 5TW

G E Robinson, MRCOG, research fellow

W Bounds, SCM, research coordinator

J Guillebaud, FRCOG,

medical director

Haematology Department,

University College and

Middlesex School of

Medicine, London W1

T Burren, BSC, research

assistant

I J Mackie, BSc, lecturer

$\mathrm{K}$ Walshe, FIMLS, senio

medical laboratory scientific

officer

R Faint, BSC, research

assistant

S J Machin, FRCPATH, reader

Correspondence to:

Mr J Guillebaud, Margaret

Pyke Centre, 15 Batemans

Buildings, Soho Square,

London W1V 5TW.

BMF 1991;302:269-71

\title{
Changes in haemostasis after stopping the combined contraceptive pill: implications for major surgery
}

\author{
G E Robinson, T Burren, I J Mackie, W Bounds, K Walshe, R Faint, J Guillebaud, S J Machin
}

\section{Abstract}

Objective-To investigate the changes in haemostasis in the three months immediately after stopping the combined contraceptive pill.

Design-Prospective randomised study.

Setting-Family planning centre in London.

Subjects -24 women aged $35-45$ investigated before, during, and after six months' use of combined oral contraceptives containing $30 \mu \mathrm{g}$ ethinyl oestradiol together with the progestogens desogestrel or gestodene.

Main outcome measures and results-Blood samples were taken immediately before and after six months of oral contraceptive use and one, two, four, six, eight, and 12 weeks after the pill had been stopped. During the six months of oral contraceptive use the plasma concentration of factor $X$ and fibrinogen increased and that of antithrombin III decreased. Between two and six weeks after stopping the pill a rebound phenomenon occurred with plasma concentrations of antithrombin III increasing (mean change from baseline at two weeks $0.06 \mathrm{IU} / 1$ and at six weeks $0 \cdot 10 \mathrm{IU} / \mathrm{l}$ ) and fibrinogen decreasing $(0.26 \mathrm{~g} / \mathrm{l}$ change at two weeks and $0.40 \mathrm{~g} / 1$ at six weeks). Factor $\mathbf{X}$ concentrations fell gradually and the values at eight weeks were not significantly different from those found before the combined pill was started.

Conclusion-The combined pill should be stopped at least four weeks before major surgery, which carries the risk of postoperative thrombosis, to allow the potentially prothrombotic haemostatic changes that occur during its use to be corrected.

\section{Introduction}

The introduction and widespread use of the combined oral contraceptive has been associated with an increase in venous thromboembolism. Epidemiological studies conducted mainly in the 1960s and early 1970 s suggest that this increased risk (approximately fourfold) is unrelated to duration of oral contraceptive use or smoking habits. ${ }^{1}$ The reduction in the dose of ethinyloestradiol in combined pill preparations has, however, been shown to be associated with a reduction in morbidity from venous thromboembolism, ${ }^{2}$ implicating the oestrogen component of the oral contraceptive in the pathogenesis of thromboembolism.

Several studies have shown that women taking combined oral contraceptives show changes in haemostasis. The plasma concentrations of the coagulation factors I (fibrinogen), II, VII, IX, X, and XII have consistently been reported to increase ${ }^{3-5}$ together with an associated decrease in antithrombin III concentration. ${ }^{45}$ These changes may predispose to venous thromboembolism, especially if not balanced by an increase either in fibrinolytic activity or of other inhibitory proteins of the coagulation cascade, such as protein C.

Major surgery is a recognised risk factor for venous 
thromboembolism, but there is debate as to whether use of the combined pill at the time of operation increases the risk further. ${ }^{6-10}$ Most surgeons would advise that the combined oral contraceptive should be stopped for at least four to six weeks before major surgery, ${ }^{11} 12$ although the evidence to support this is largely empirical. It has often been recommended that emergency procedures with a high risk of thromboembolic complications should be covered with low dose heparin prophylaxis, ${ }^{6}$ but this view has recently been challenged. ${ }^{9}$

Previous studies of haemostasis in users of the combined pill have concentrated on younger women and none have specifically investigated the changes that occur when women stop taking the pill. Use of the pill by older women is likely to increase because the United States Food and Drug Administration's fertility and maternal health drugs advisory committee has recently recommended removing the accepted upper age limit for its use in healthy non-smoking women..$^{13}$ We investigated, as part of a larger study of the effects of two modern low dose oral contraceptives in older women, the changes in certain coagulation factors that occurred when women stopped the combined pill.

\section{Patients and methods}

Twenty four women aged 35-45 who had taken either Femodene $(30 \mu \mathrm{g}$ ethinyloestradiol, $75 \mu \mathrm{g}$ gestodene) or Marvelon (30 $\mu \mathrm{g}$ ethinyloestradiol, $150 \mu \mathrm{g}$ desogestrel) for six months participated in this study. The women were all non-smokers, had a body mass index between 19 and 25 , were not vegetarians, and had not taken hormonal preparations for at least three months before the start of the study. Study visits occurred in the luteal phase of the cycle before the pill was started, in the last seven days of taking the pill in cycle 6 , and one, two, four, six, eight, and 12 weeks after the last pill had been taken. The visits took place in the morning between 8 and $10 \mathrm{am}$. After the subject had rested for 30 minutes blood was taken by clean venepuncture into $0.106 \mathrm{M}$ trisodium citrate (nine volumes blood to one volume anticoagulant) and immediately centrifuged at $2000 \mathrm{~g}$ at room temperature. Plasma was stored in aliquots at $-70^{\circ} \mathrm{C}$ until analysis.

Clottable fibrinogen was determined by the Clauss assay, ${ }^{14}$ and its antigen was measured in selected samples by immunoelectrophoresis ${ }^{15}$ using commercial antiserum (Dako Ltd, High Wycombe). Factor VII and factor $\mathrm{X}$ were measured by one stage clotting

Mean changes from baseline for coagulation factors in women aged 35-45 after stopping combined pill

\begin{tabular}{|c|c|c|c|c|c|c|c|c|}
\hline & \multirow[b]{2}{*}{$\begin{array}{c}\text { Baseline value } \\
(n=24)\end{array}$} & \multirow[b]{2}{*}{$\begin{array}{l}\text { After } 6 \text { months on pill } \\
\qquad(\mathrm{n}=22)\end{array}$} & \multicolumn{6}{|c|}{ Weeks since pill stopped } \\
\hline & & & $\begin{array}{c}1 \\
(n=24)\end{array}$ & $\begin{array}{c}2 \\
(\mathbf{n}=23)\end{array}$ & $\begin{array}{c}4 \\
(n=22)\end{array}$ & $\begin{array}{c}6 \\
(n=24)\end{array}$ & $\begin{array}{c}8 \\
(n=20)\end{array}$ & $\begin{array}{c}12 \\
(n=20)\end{array}$ \\
\hline \multicolumn{9}{|c|}{ Fibrinogen $(\mathrm{g} / \mathrm{l})$ : } \\
\hline Mean & $2 \cdot 18$ & $0 \cdot 35^{\star}$ & $0 \cdot 08$ & $-0 \cdot 26^{\star}$ & $-0 \cdot 19$ & $-0 \cdot 40^{\star}$ & -0.08 & $-0 \cdot 23^{\star}$ \\
\hline SD & 0.44 & 0.52 & 0.54 & $0 \cdot 48$ & 0.56 & $0 \cdot 54$ & 0.49 & 0.49 \\
\hline \multicolumn{9}{|c|}{ Factor VII (IU/1): } \\
\hline Mean & 0.90 & 0.01 & -0.02 & 0.02 & $0 \cdot 00$ & -0.03 & 0.01 & 0.00 \\
\hline $\mathrm{SD}$ & $0 \cdot 15$ & $0 \cdot 19$ & $0 \cdot 20$ & $0 \cdot 19$ & $0 \cdot 14$ & $0 \cdot 20$ & $0 \cdot 22$ & $0 \cdot 18$ \\
\hline \multicolumn{9}{|c|}{ Factor $\mathrm{X}(\mathrm{IU} / \mathrm{l})$ : } \\
\hline Mean & 1.05 & $0 \cdot 32^{\star}$ & $0 \cdot 24^{\star}$ & $0 \cdot 17^{\star}$ & $0 \cdot 11$ & $0 \cdot 12^{\star}$ & 0.09 & $0 \cdot 11$ \\
\hline SD & $0 \cdot 15$ & $0 \cdot 28$ & $0 \cdot 24$ & $0 \cdot 24$ & $0 \cdot 19$ & $0 \cdot 20$ & $0 \cdot 22$ & 0.09 \\
\hline \multicolumn{9}{|c|}{ Antithrombin III (IU/l): } \\
\hline Mean & 1.03 & $-0 \cdot 09^{\star}$ & $-0 \cdot 04$ & 0.06 & $0.09^{\star}$ & $0 \cdot 10^{\star}$ & 0.05 & 0.04 \\
\hline SD & $0 \cdot 15$ & $0 \cdot 14$ & $0 \cdot 20$ & $0 \cdot 24$ & $0 \cdot 19$ & $0 \cdot 20$ & $0 \cdot 22$ & $0 \cdot 22$ \\
\hline \multicolumn{9}{|c|}{ Protein C (IU/1): } \\
\hline Mean & 0.87 & $0 \cdot 04$ & $0 \cdot 07^{\star}$ & $0 \cdot 10^{\star}$ & 0.01 & 0.04 & -0.01 & 0.03 \\
\hline SD & $0 \cdot 15$ & $0 \cdot 14$ & $0 \cdot 15$ & $0 \cdot 14$ & $0 \cdot 14$ & $0 \cdot 15$ & $0 \cdot 18$ & $0 \cdot 13$ \\
\hline \multicolumn{9}{|c|}{ Plasminogen (IU/I): } \\
\hline Mean & 1.00 & $-0 \cdot 06$ & -0.05 & 0.01 & -0.02 & -0.03 & 0.01 & 0.01 \\
\hline SD & 0.20 & $0 \cdot 23$ & $0 \cdot 20$ & $0 \cdot 19$ & $0 \cdot 14$ & $0 \cdot 15$ & $0 \cdot 18$ & $0 \cdot 18$ \\
\hline \multicolumn{9}{|c|}{$\alpha$-2-Antiplasmin (IU/l): } \\
\hline Mean & 1.03 & $0 \cdot 08$ & $0 \cdot 16^{\star}$ & 0.07 & $0 \cdot 12^{\star}$ & 0.05 & 0.02 & 0.04 \\
\hline SD & $0 \cdot 15$ & $0 \cdot 19$ & $0 \cdot 20$ & $0 \cdot 19$ & $0 \cdot 19$ & $0 \cdot 20$ & $0 \cdot 22$ & $0 \cdot 18$ \\
\hline
\end{tabular}

${ }^{\star}$ Significant change from baseline, $0 \cdot 01>\mathrm{p}<0 \cdot 05$. assays. ${ }^{16}$ Antithrombin III, plasminogen, $\alpha$-2-antiplasmin, and protein $\mathrm{C}$ were determined by amidolytic microtitre assays. ${ }^{17}$

Statistical analysis was performed by the repeated measures analysis of variance. ${ }^{18}$ Duncan's multiple range test was used to control the overall level of significance for repeated testing. The mean of the changes from each woman's baseline value was used in the analysis as the main purpose of the study was to investiate the changes in the haemostatic variables once the combined pill was stopped.

The study was approved by the Middlesex Hospital ethics committee.

\section{Results}

Of the 24 women in the study, 13 took Marvelon and 11 took Femodene. Fourteen women completed the entire study, attending each visit; seven women missed one study visit, and three women missed two visits. Thus data for analysis was available from 24 women for the visit before the pill was started; 22 women for the visit after six months' use of the combined pill; and from $24,23,22,24,20$, and 20 women for the visits one, two, four, six, eight, and 12 weeks, respectively, after the combined pill was stopped. The statistical analysis studied change within patients. At each time point the comparison relates those women who attended that study visit with their own baseline values. Although all the available data were analysed and presented to avoid bias by exclusion of dropouts, anaiysis restricted to the 14 women who attended each study visit showed the same trends as those presented here.

There was no significant difference between the two groups of women taking either of the combined oral contraceptive preparations in the changes seen in the haemostatic system when the combined pill was stopped. When the data from the two groups were combined, however, significant differences were found in the haemostatic variables measured both during and after oral contraceptive use as compared with baseline values.

The table shows mean baseline concentrations for each of the haemostatic variables measured, together with the mean change in concentration both during and for the 12 weeks after the combined pill was stopped. The more important changes are illustrated graphically in the figure.

Fibrinogen concentrations increased significantly in the six months of combined pill use but within one week of stopping the pill there was no difference from the baseline value. At two, six, and 12 weeks, however, concentrations were significantly below baseline, and fibrinogen antigen was closely correlated with clottable fibrinogen, indicating reduced synthesis.

Factor X concentrations increased significantly during pill use and gradually fell after the pill was stopped. At eight weeks there was no significant difference from baseline.

The plasma concentration of antithrombin III fell during oral contraceptive use but showed no significant difference from baseline within one week of stopping the pill. At four and six weeks the concentration was significantly higher than baseline.

Factor VII, protein $C$, and $\alpha$-2-antiplasmin did not show a significant change during the six months of pill use, but protein $C$ and $\alpha$-2-antiplasmin showed signifcant but transient increases after the pill was stopped.

\section{Discussion}

An increase in factor $\mathrm{X}$ and fibrinogen concentrations together with a reduction in antithrombin III concentration was found during oral contraceptive use. The 

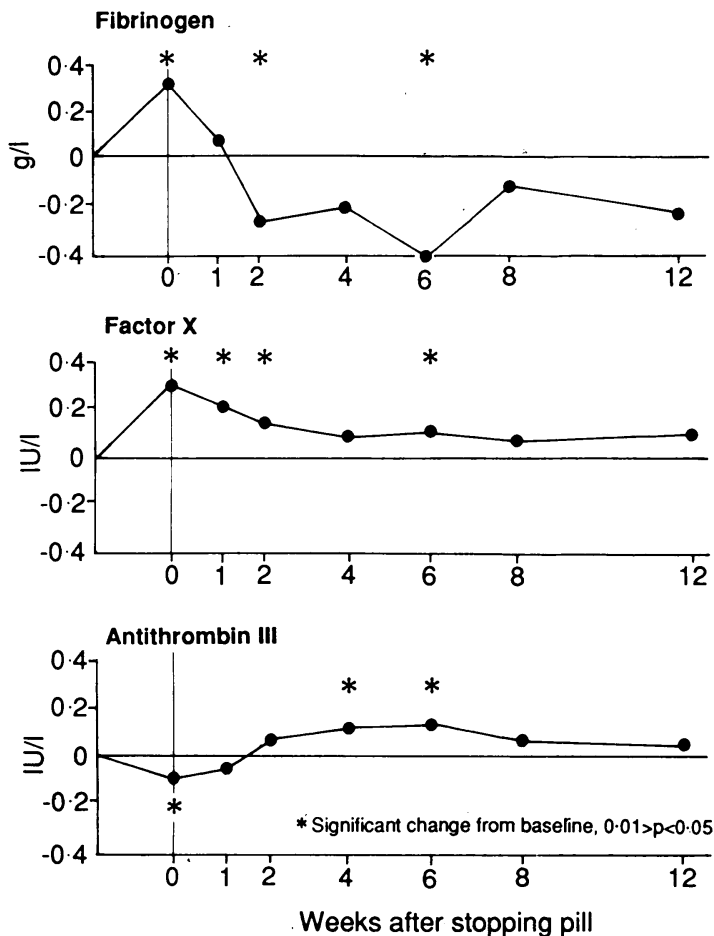

Mean changes from baseline for coagulation factors in women aged 35-45 after stopping combined pill. Baseline values were obtained before starting six cycles of the pill

plasma concentrations of fibrinogen and antithrombin III were not significantly different from baseline within one week of stopping the combined pill, but the factor $\mathrm{X}$ concentration was significantly raised until eight weeks. A "rebound" phenomenon was shown for both fibrinogen and antithrombin III, occurring between two and six weeks after stopping the pill, and for fibrinogen this rebound was still present after three months. The changes seen with the clottable fibrinogen technique correlated with levels detected by an immunological technique, suggesting that altered synthesis or metabolism was most probably a direct result of the steroid. This rebound phenomenon is being investigated further in a larger study. Its significance remains unclear, as does the increase in $\alpha-2$ antiplasmin and protein $\mathrm{C}$ seen once the oral contraceptive was stopped.

The participants in this study were aged $35-45$. The changes in the haemostatic system during oral contraceptive use are similar to those seen in younger women using the same preparations. It is thus unlikely that the changes found in the study group will differ greatly in younger women.

This study showed that changes in concentrations of coagulation factors occurring during use of the pill take several weeks to return to baseline values. Although the mean values for the coagulation factors were all within the normal range, the changes that occurred during oral contraceptive use-an increase in the coagulant factors fibrinogen and factor $\mathrm{X}$, together with a reduction in antithrombin III not balanced by an increase in protein $\mathrm{C}$ or plasminogen levels-are potentially thrombogenic. We suggest that the changes shown in women using oral contraceptives add to the known thromboembolic risks of major surgery. This study implies that surgery is best performed after the combined pill has been stopped for at least four weeks. At this time fibrinogen concentration is low, antithrombin III concentration is high, and factor $\mathrm{X}$ concentration has nearly returned to control.

We thank the Margaret Pyke Memorial Trust and Schering Health Care for financial assistance and provision of oral contraceptive supplies. We are grateful to Mr B Newman, University College London, and Mr A Pearce, Schering Health Care plc, for statistical advice and for analysing the data.

1 Realini JP, Goldzieher JW. Oral contraceptives and cardiovascular disease-a critique of the epidemiological studies. Am $\mathcal{F}$ Obstet Gynecol 1985;152 729-98.

2 Bottiger LC, Bowman G, Eklund G, Westerholm B. Oral contraceptives and cardiovascular disease: effects of lowering oestrogen content. Lance $1980 ; 1: 1097-101$.

3 Bonnar J. Coagulation effects of oral contraception. Am $\mathcal{F}$ Obstet Gynecol 1987; 157:1042-8.

4 Mammon EF. Oral contraceptives and blood coagulation: a critical review. Am f Obstet Gynecol 1982;142:781-90.

5 Cohen H, Mackie IJ, Walshe K, Gillmer MDG, Machin SJ. A comparison of the effects of two triphasic oral contraceptives on haemostasis. Brf

6 Sagar S, Thomas DP, Stamatakis JD, Kakkar VV. Oral contraceptives, antithrombin III activity and postoperative deep-vein thrombosis. Lancel 1976;i:509-11.

7 Gallus AS, Chooi CC, Konetschnik F, Goodhall KT. Oral contraceptives and surgery: reduced antithrombin and antifactor $\mathrm{Xa}$ levels withou postoperative venous thrombosis in low risk patients. Thromb Res 1984;35:513-26.

8 Vessey M, Mant D, Smith A, Yeates D. Oral contraceptives and venous thromboembolism: findings in a large prospective study. $B M \mathcal{F} 1986 ; 292$ : 526.

9 Sue-Ling H, Hughes LE. Should the pill be stopped preoperatively? $B M$ 1988;296:447-8.

10 Guillebaud J. Should the pill be stopped preoperatively? BMF 1988;296: 786-7.

11 Hawkins DF, Elder M. Human fertility control and practice. London: Butterworth, 1979.

12 Guillebaud J. Surgery and the pill. BMF 1985;291:498-9.

13 Anonymous. US Food and Drug Administration's Fertility and Maternal Health Drugs Advisory Committee. Outlook 1989;7:10.

14 Von-Clauss A. Gerinnungsphysiologische schnellmethode zur bestimmun des fibrinogens. Acta Haematol (Basel) 1957;17:237-46.

15 Mancini G, Carbonara AO, Heremans JF. Immunochemical quantitation of antigens by single radial immunodiffusion. Immunochemistry 1965;2:235-54 16 Giddings JC. Hereditary coagulation disorders: laboratory techniques. In Thompson JM, ed. Blood coagulation and haemostasis. A practical guide. Edinburgh: Churchill Livingstone, 1980:138.

17 Machin SJ, Mackie I. Haemostasis. In: Chanarin I, ed. Laboratory haematology. Edinburgh: Churchill Livingstone, 1989:263-399.

18 Koch GG, Ingrid AA, Stokes ME, Gillings DB. Some views on parametric and non-parametric analysis for repeated measurements and selected bibliography. International Statistical Review 1980;48:249-65.

(Accepted 17 November 1990)
A protest, influentially signed, is about to be addressed to the Home Secretary against the withdrawal of the muzzling regulations for the following reasons: -1 . That until muzzling for twelve months be enforced simultaneously throughout Great Britain, followed by permanent quarantine, the extinction of rabies will be impossible, and that deaths from hydrophobia will by consequence inevitably recur in London. 2 . That it has been abundantly proved by the experience of London alone, during the epidemics of 1885-86 and 1889-90, that deaths from hydrophobia cease after a period of muzzling, and that it is, therefore, painful to contemplate the risk of a recrudescence of the disease about to be incurred by the inhabitants of the metropolis, now that the muzzling regulation is replaced by a system which has utterly broken down in Vienna, Belgium, and Bradford. The memorialists also add that, after eighteen months' experience, many dog owners are now of opinion that muzzling in large cities is of inestimable benefit not only to mankind, who are thereby saved from the chance of contracting one of the most painful of diseases, but also to dogs, who are prevented by the muzzle from fighting with each other, from picking up garbage (by which they often suffer intensely), and from the risk of poisoning. As to the temporary good effects of the muzzling order while it lasted, Mr. Blanchard Wontner's statement before the magistrate at the Marylebone Police Court on the results attained in London during the year are very instructive. He said that in the year before the order was made there were 400 cases of rabies reported, mainly in London, and the number not reported would no doubt be large. During the three-quarters of the following year the number was reduced to 120 , and in the four quarters of the year just closed the number of cases of rabies had been reduced to $15,13,8$, and nil.

(British Medical fournal 1891;i:82) 